\title{
Design and Development of a Novel Anticancer Peptide from Human Gut Microbiome by using Recombinant Protein Engineering
}

\author{
Thi Kim Cuc Nguyen ${ }^{1}$, Thu Thuy Pham ${ }^{1}$, Thi Bich Mai Huynh ${ }^{1}$, Thanh Hoang Tran ${ }^{1}$, \\ Michael Packianather ${ }^{2}$, Chi Hieu Le ${ }^{3}$, Van Duy Nguyen ${ }^{1,2,3}$ \\ ${ }^{1}$ Institute of Biotechnology and Environment, Nha Trang University, Nha Trang, Vietnam \\ ${ }^{2}$ School of Engineering, Cardiff University, Cardiff, United Kingdom \\ ${ }^{3}$ Faculty of Engineering and Science, University of Greenwich, Chatham, Kent, United \\ Kingdom \\ duynv@ntu.edu.vn; V.Nguyen@gre.ac.uk
}

\begin{abstract}
Human microbiota is a microbial community that lives on and in the human body. It has received considerable attention and research efforts over the past decade because it exerts a major impact on human health, from metabolism to immunity. In a recent study, we identified novel anticancer Azurin-like peptides from the human gut microbiome using combined molecular biology and bioinformatics based approaches. Herein, we present the cloning, expression and partial purification of one of these peptides as a case study towards the design and development of novel anticancer peptide drugs by the use of recombinant protein engineering. Firstly, the vector pET42a $(+)$ is used for the cloning of a peptide Cnazu8 encoded by p2seq12 (cnazu8) from Clostridium nexile DSM 1718 in E. coli OmniMAX. Secondly, this vector is further used for expression in E. coli BL21 (DE3). Finally, protein purification is performed in a HisPur NiNTA column (Thermo). The results show that the plasmid pDT008 allows Cnazu8 to express in fusion with GST-6xHis-TEV in E. coli. The optimal conditions for expression of the fusion peptide GST-6xHis-TEV-Cnazu8 (36.7 $\mathrm{kDa}$ ) include IPTG at $0.05 \mathrm{mM}$ and the temperature at $37^{\circ} \mathrm{C}$. However, most of the expected proteins are expressed in the insoluble forms. Thus, a sonication method for cell disruption is developed to increase the solubility of the desired proteins. The purification results in a relatively low amount of desired fusion proteins. Thus, the purification optimization and anticancer bioassays of Cnazu8 are required to further consider as a novel anticancer drug candidate.

Keywords: anticancer peptide, Clostridium nexile, expression, human gut microbiome, purification.
\end{abstract}

\section{Introduction}

Cancer is one of the leading causes of deaths in the world and in Vietnam. The major treatment method is tumor surgical resection followed by radiation and chemotherapy [1]. However, these methods can cause side effects to normal cells and resistant to drugs. Thus, many efforts have been made to develop more effective treatments, including biomedical therapy based on anticancer peptides from bacteria. 
Azurin, a bacteriocin produced by the pathogenic bacterium Pseudomonas aeruginosa, can reveal selectively cytotoxic and induce apoptosis in cancer cells but cause no apparent effects on normal cells [2]. After overcoming two phase I trials, a functional region of Azurin at amino acids from 50 to 77 (p28) is recommended to use in cancer therapy by several US patents [3] and has been approved as a drug for the treatment of brain tumor glioma by FDA [4]. A recent study indicated that Azurin may be used as an adjuvant to improve the treatment effect to lung cancer [5].

We have recently screened Azurin-like bacteriocins from human gut microbiome with potential anticancer activity [6-7]. Cnazu8 encoded by the $p 2 s e q 12$ (cnazu8) gene in Clostridium nexile DSM 1787 is one of these peptides. In order to design and develop a novel anticancer peptide drug based on Recombinant Protein Engineering, major problems such as the low stability and solubility of recombinant proteins and their unspecific binding during purification must be addressed. In this study, we have overcome these problems to conduct successfully the cloning and expression of the cnazu 8 gene in E. coli and the partial purification of the respective protein.

\section{Materials and Methods}

\subsection{Plasmid, enzyme, bacterial strain, oligonucleotide and synthetic gene}

Plasmid pET42a $(+)$ (Novagen) is used for gene cloning and protein expression in $E$. coli (Fig. 1). Enzymes include Pfu DNA polymerase (New England Biolabs), My Taq DNA polymerase (Bioline), BamHI and EcoRI (Fermentas).

E. coli OmniMAX (Invitrogen) for cloning and E. coli BL21(DE3) (Novagen) for gene expression were grown aerobically in Luria-Bertani (LB) broth at $37^{\circ} \mathrm{C}$.

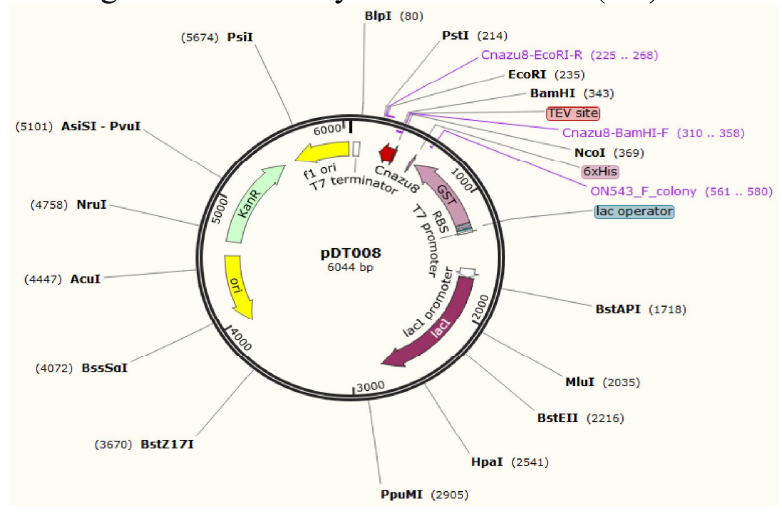

Fig. 1. pDT008 (T7- GST-6xHis-TEV-Cnazu8, Kan)

A cnazu8-carrying synthetic DNA fragment and oligonucleotide primers (Macrogen, Korea) were used in PCR to obtain cnazu8 gene. Primers include Cnazu8_BamHI_F (GTA CTT CCA GGG ATC CAT GAA TCT GAT ATA CTG TAA ACA CTA CAG AAA G); Cnazu8_EcoRI_R (GGC CTG TAC AGA ATT CTT AAT 
CAC TAA TTC TGA TTT GAA TTT GG); and pET42a(+)_F _colony (GTT TGG TGG TGG CGA CCA TC).

\subsection{The construction of expression plasmid}

Cnazu 8 gene was obtained by using PCR method based on cnazu8-carrying synthetic DNA fragment with specific primers Cnazu8_BamHI_F and Cnazu8_EcoRI_R. The purified amplicons and pET42a $(+)$ were then digested with EcoRI and BamHI. Cnazu8 was ligated into pET42a $(+)$ by T4 DNA ligase (Fermentas) to construct a recombinant vector called pDT008 (Fig. 1). The pDT008 was transformed into the competent $E$. coli OmniMAX and $E$. coli BL21 (DE3). Transformants were screened by colony PCR and then recombinant colonies were purified by the GeneJET Plasmid Miniprep Kit (Bioline). The recombinant vectors were confirmed by PCR and DNA sequencing (Macrogen, Korea).

\subsection{The expression of bacteriocin Cnazu8 in E. coli}

The pDT008-carrying E. coli strain BL21(DE3) was selected on LB agar plates with kanamycin $(30 \mu \mathrm{g} / \mathrm{ml})$. The expression was induced by the addition of isopropyl- $\beta-\mathrm{D}-$ thiogalactopyranoside (IPTG) and cultures were grown for $3 \mathrm{~h}$ at $37^{\circ} \mathrm{C}$. Two $\mathrm{ml}$ of cultures were collected and bacterial cell pellets were harvested by centrifugation at $8000 \times \mathrm{g}$ for $30 \mathrm{~min}$ at $4^{\circ} \mathrm{C}$, followed by suspended in Tris-Cl buffer $(500 \mathrm{mM} \mathrm{NaCl}$, $5 \%$ glycerol), $\mathrm{pH} 8.0$ and sonicated on ice. The cell pellet and supernatant were harvested by the same centrifugation. Protein solutions were analyzed by SDS-PAGE and stained with Coomassie Brilliant Blue.

To find the optimal concentration of inducer for expression, the final IPTG concentrations of $0.01,0.05,0.1$ and $0.5 \mathrm{mM}$ in cultures were examined at $37^{\circ} \mathrm{C}$ in the mid exponential phase for $3 \mathrm{~h}$ with shaking at $150 \mathrm{rpm}$. To find the optimal induction temperature, cultures were incubated at three different temperatures $\left(23,30\right.$ and $\left.37^{\circ} \mathrm{C}\right)$ with the defined optimal inducer concentration at the same condition.

\subsection{The extraction and purification of bacteriocin Cnazu8}

The extraction of the fusion Cnazu8 was performed by sonication as described above with an exception that a step of freezing the bacterial cell pellet at $-40^{\circ} \mathrm{C}$ for overnight before sonication was added. The supernatant containing the soluble Cnazu8 was purified by using a HisPur Ni-NTA column (Thermo, USA) according to the manufacturer instructions. Protein fractions were analyzed by SDS-PAGE.

\section{Results and Discussions}

\subsection{The cloning of cnazur gene}

The cnazu 8 gene ( $134 \mathrm{bp}$ ) was obtained by using PCR and analyzed by agarose gel electrophoresis (data not shown). Then it was cloned into the plasmid pET42a $(+)$ for construction of the recombinant plasmid pDT008, which was used to transform into the cloning host E. coli OmniMAX and the expression host E. coli BL21 (DE3). These purified recombinant plasmids were confirmed by using colony PCR method with the expected sizes of the PCR products (356 bp) (data not shown). These results in 
combination with the DNA sequencing (data not shown) confirmed that cnazu 8 was successfully cloned into pET42a(+) in E. coli BL21.

\subsection{Inducer concentration optimization}

SDS-PAGE analysis (Fig. 2) showed that the expected fusion Cnazu8 (36.7 kDa) was highly expressed with IPTG induction at the concentrations of $0.5,0.1$ and 0.05 $\mathrm{mM}$ but lowly expressed at $0.01 \mathrm{mM}$ IPTG. The expected protein was less expressed in the control sample without IPTG induction. The expected fusion Cnazu 8 was not observed in all supernatants (lanes S) but it was observed in the pellets (lanes P). These results have showed that the IPTG concentration of $0.05 \mathrm{mM}$ is enough to induce the recombinant GST-6xHis-TEV-Cnazu8 expression and this protein has a major fraction existing in pellet in an insoluble status. Thus, it is necessary to investigate the optimal temperature in this case after an induction with $0.05 \mathrm{mM}$ IPTG.



Fig. 2. SDS-PAGE (12\%) analysis of Cnazu8 expression in E. coli BL21 (DE3) at the different concentrations of IPTG. M: molecular weight marker; T: total protein for $3 \mathrm{~h}$ induction at at $37^{\circ} \mathrm{C}$; P: pellet for $3 \mathrm{~h}$ induction at $37^{\circ} \mathrm{C}$; $\mathrm{S}$ : supernatant for $3 \mathrm{~h}$ induction at $37^{\circ} \mathrm{C}$; (-) control (uninduced). The expected protein band is indicated with arrows.

\subsection{Temperature optimization}

The results revealed that the expression of the recombinant Cnazu8 was the highest at $37^{\circ} \mathrm{C}$ under the induced IPTG concentration at $0.05 \mathrm{mM}$ and decreased gradually from $30^{\circ} \mathrm{C}$ to $23^{\circ} \mathrm{C}$ with the same IPTG concentration (Fig. 3). However, the fusion Cnazu8 was detected in the component of pellet (lanes P, Fig. 3) under induction at all three temperatures $\left(23^{\circ} \mathrm{C}, 30^{\circ} \mathrm{C}\right.$ and $\left.37^{\circ} \mathrm{C}\right)$, but not in the components of supernatants (lanes S, Fig. 3). These results indicated that this fusion protein was insoluble, thus, it was very difficult to purify it. Therefore, it is required to improve the solubility of the fusion Cnazu8 by using other purification methods.

$E$. coli is the most frequently employed host with many available expression systems for producing recombinant proteins. However, its use for the production of recombinant proteins is facing a number of practical problems. For example, the stability and solubility of recombinant proteins produced in E. coli can be low due to proteolytic degradation and the formation of inclusion bodies, respectively [8]. The major factors affecting the expression and the solubility of recombinant protein are inducer concentration and induction temperature [9]. Higher temperatures for postinduction $\left(37^{\circ} \mathrm{C}\right)$ often lead to more biomass and more recombinant protein yield [8]. 
However, reduced or low temperatures can be effective in improving the solubility of some proteins that are difficult to express [10].

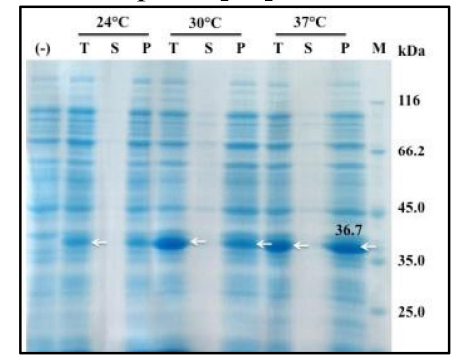

Fig. 3. SDS-PAGE (12\%) analysis of the recombinant Cnazu8 expression in E. coli BL21 (DE3) at the different temperature conditions. M: molecular weight marker; T: total protein for $3 \mathrm{~h}$ induction at at $37^{\circ} \mathrm{C}$; P: pellet for $3 \mathrm{~h}$ induction at $37^{\circ} \mathrm{C}$; $\mathrm{S}$ : supernatant for $3 \mathrm{~h}$ induction at $37^{\circ} \mathrm{C}$; (-) control (uninduced).

In the present study, we found that the best expression of recombinant GST-6xhisTEV-Cnazu 8 occurred at $37^{\circ} \mathrm{C}$ with the induction by IPTG at final concentration of $0.05 \mathrm{mM}$. However, this recombinant Cnazu 8 was in insoluble form as inclusion bodies existing in cell pellet. Reducing temperature to $30^{\circ} \mathrm{C}$ and $23^{\circ} \mathrm{C}$ for post-induction also did not increase the yield of soluble protein fractions. There are two approaches to overcome these problems that include further expression optimization of soluble recombinant with other factors (culture media, host strains, expression system, etc) and extraction optimization for improving the solubility of protein [10]. Here we performed a minor modification in extraction method, freezing the cell pellet at $-40^{\circ} \mathrm{C}$ for overnight before sonication, thus improved significantly the yield of soluble Cnazu8.

\subsection{The extraction and purification of the fusion Cnazu8}

The soluble fusion Cnazu8 was highly expressed in components of supernatant that were obtained from the sonication with freezing of the cell pellet (lane S3, Fig. 4 (left)), but very lowly expressed in components of supernatant obtained from the sonication without freezing of the cell pellet (lane S2, Fig. 4 (left)). The results showed that the solubility of the Cnazu 8 was improved significantly by the combination of the freezing of the cell pellet with sonication.

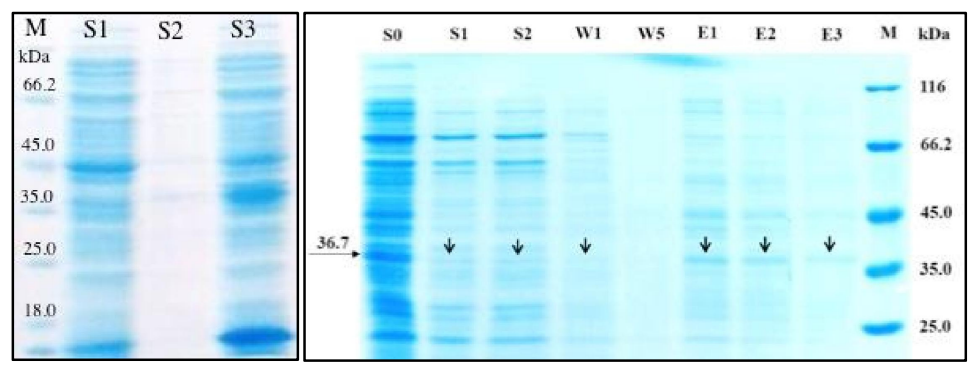

Fig. 4. SDS-PAGE (12\%) of soluble fusion protein Cnazu8 in E. coli BL21 (DE3) obtained by sonication (left) and purified by HisPur Ni-NTA kit (right). M: molecular 
weight marker. Left, S1: soluble protein of control (uninduced); S2: soluble protein extract by sonication without storing at $-40^{\circ} \mathrm{C} ; \mathrm{S} 3$ : soluble protein extract by sonication stored at $-40^{\circ} \mathrm{C}$.

Right, $\mathrm{S}_{0}$ : pre-purified sample; $\mathrm{S}_{1-2}$ : Samples after column binding (the first time and the second time); $\mathrm{W}_{1,5}$ : samples after column washing (the first time and the fifth time); E1-3: samples of eluted fractions (the first time to the third time).

The results from Fig. 4 (right) indicated that the expected protein band $(36.7 \mathrm{kDa})$ presented in all elution fractions. This suggested that the GST-6xHis-TEV-Cnazu8 bound on column and was eluted from column but the binding of this protein on column was low efficient and non-specific.

According to theory, the fusion GST-6xhis-TEV-Cnazu8 can be purified by specific binding of his-tag with immobilized metal-ion in Ni-NTA column, but our results have indicated that there is at least an unspecific protein in Ni-NTA column. This lead to the low binding efficiency of GST-6xhis-TEV-Cnazu8 with immobilized metal-ion in NiNTA column. Several approaches have been used to reduce the unspecific binding of proteins, including the use of higher imidazole concentration in the washing buffer. Moreover, the concentration of imidazole for washing and elution is a powerful tool to increase purity and specificity in the purification process [11]. Therefore, further studies are required to define the optimal conditions of purification method and evaluate the anticancer activity of this purified protein.

In conclusions, we report the successful cloning and expression of the recombinant Cnzu8 protein from Clostridium nextile DMS in E. coli. This recombinant protein is highly expressed with the optimal conditions including $0.05 \mathrm{mM}$ IPTG and the temperature at $37^{\circ} \mathrm{C}$ and is extracted by the sonication of biomass stored at $-40^{\circ} \mathrm{C}$.

\section{Acknowledgment}

This work was supported by a grant no.106-YS.04-2014.40 from the Vietnam National Foundation for Science and Technology Development (NAFOSTED).

\section{References}

1. Chakrabarty, A.M., Bernardes, N., Fialho, A.M.: Bacterial proteins and peptides in cancer therapy: today and tomorrow. Bioengineered. 5(4), 234-42 (2014).

2. Taylor, B.N., Mehta, R.R., Yamada, T., Lekmine, F., Christov, K., Chakrabarty, A.M., Green, A., Bratescu, L., Shilkaitis, A., Beattie, C.W., Das Gupta, T.K..: Noncationic Peptides Obtained From Azurin Preferentially Enter Cancer Cells. Cancer Res 69(2), 53746 (2009).

3. Fialho, A.M., Bernardes, N., Chakrabarty, A.M.: Recent patents on live bacteria and their products as potential anticancer agents. Recent Pat Anticancer Drug Discov 7(1), 31-55 (2012).

4. Fialho, A.M., Bernardes, N., Chakrabarty, A.M.: Exploring the anticancer potential of the bacterial protein azurin. AIMS Microbiol 2(3), 292-303 (2016). 
5. Bernardes, N., Abreu, S., Carvalho, F.A., Fernandes, F., Santos, N.C., Fialho, A.M.: Modulation of membrane properties of lung cancer cells by azurin enhances the sensitivity to EGFR-targeted therapy and decreased $\beta 1$ integrin-mediated adhesion. Cell Cycle 15(11): 1415-24 (2016).

6. Nguyen, V.D., Nguyen, H.H.C.: Molecular screening of Azurin-like anticancer bacteriocins from human gut microfora using bioinformatics. Advances in Intelligent Systems and Computing 358, 219-229 (2015).

7. Nguyen, C., Nguyen, V.D.: Discovery of azurin-like anticancer bacteriocins from human gut microbiome through homology modeling and molecular docking against the tumor suppressor p53. Biomed Res Int 2016: 8490482 (2016).

8. Choi, J.H., Keum, K.C., Lee, S.Y.: Production of recombinant proteins by high cell density culture of Escherichia coli. Chemical Engineering Science 61, 876-885 (2006).

9. Vincentelli, R., Cimino, A., Geerlof, A., Kubo, A., Satou, Y., Cambillau, C.: Highthroughput protein expression screening and purification in Escherichia coli. Methods 55(1), 65-72 (2006).

10. Sheng, J., Yu, H., Li, J., Sheng, G., Zhou, L., Lu, Y.: Cloning and expression of the human augmenter of liver regeneration at low temperature in Escherichia coli. J Biochem Biophys Methods 70(3), 465-470 (2007).

11. Arnau, J., Lauritzen, C., Petersen, G.E., Pedersen J.: Current strategies for the use of affinity tags and tag removal for the purification of recombinant proteins. Protein Expr Purif 48(1), $1-13$ (2006).

\section{Conflicts of Interest Statement}

All authors have no conflicts of interest to declare. 